\title{
Ten-Year Multi-Center Survey of Infant Mortality in China
}

\author{
Long Chen ${ }^{1,2}$, Xingwang Zhu ${ }^{3}$ and Yuan Shi (iD) ${ }^{1,}$ \\ ${ }^{1}$ Department of Neonatology, Children's Hospital of Chongqing Medical University, Chongqing, China \\ ${ }^{2}$ Department of Pediatrics, Research Institute of Surgery, Daping Hospital, Third Military Medical University, Chongqing, China \\ ${ }^{3}$ Department of Pediatrics, People's Hospital of Jiulongpo, Chongqing, China \\ "Corresponding author: Department of Neonatology, Children's Hospital of Chongqing Medical University, Chongqing, China. Tel: +86-13508300283, Email: \\ petshi530@vip.163.com
}

Received 2018 April 05; Revised 2019 October 09; Accepted 2019 October 14.

\begin{abstract}
Background: The neonatal mortality rate has continually decreased over time; however, some surviving infants may die after the neonatal period due to complications.

Objectives: Objective of this study was to provide evidence to support more medical care for infants during the post-neonatal period ( $>28$ days to $<100$ days after birth).

Methods: Multi-center retrospective survey. Fourteen hospitals in china between January 1, 2004 and December 31, 2013. A total of155463 infants aged 0 - 1 year were enrolled in the survey. Among them, 959 died. Data from hospitalized infants younger than 1 year of age were collected. Mortality and its etiology during the neonatal, post-newborn, and modified infant (100 days to 1 year) period were evaluated.

Results: The total infant mortality was $6.16 \%$. Significant differences were found in the mortality rate in the three periods (10.1\% vs $6.9 \%$ vs $2.6 \%, \mathrm{P}=0.000$ ). The three main causes of death were pneumonia, congenital heart disease (CHD), and premature-associated disease (PAD) during the post-newborn period. Moreover, four major diseases simultaneously occurring during the three periods (PAD, pneumonia, sudden infant death syndrome, and CHD) showed an inverse " $U$ " shape change from the neonatal period to the modified infant period, with the highest mortality rate occurring during the post-newborn period $(\mathrm{P}<0.001)$.

Conclusions: Differences in mortality and the associated etiology during early life indicate that more medical attention should be paid to the post-newborn period. Further study is needed to better understand its clinical significance.
\end{abstract}

Keywords: Newborn, Post-Newborn, Mortality, Prematurity-Associated Disease

\section{Background}

Although the incidence of preterm births has increased in the last few decades and affected approximately $11 \%$ of all pregnancies, neonatal mortality shows a decreased trend because of general use of mechanical ventilation and exogenous surfactant replacement therapy $(1,2)$. Subsequently, preterm birth has been the most common cause of death in early life (3). Some survivors of preterm birth were afflicted by prematurity-associated complications and sequelae in childhood and/or adulthood, such as developmental retardation, bronchopulmonary dysplasia (BPD) and congenital heart disease (CHD) (4-7). Moreover, population-based epidemiological data have shown close association between growth and development in early life and health and disease in childhood and/or as adults. Some evidence has suggested that administration and medical care in the post-neonatal period might benefit these surviving infants and ultimately pro- mote their quality of life (8). Nevertheless, which life period during early life is the key period and determining its impact, remains unclear. Improved understanding of the early life period might help medical and public health personnel to make more reasonable decisions.

A new concept of life period from $>28$ days to $<100$ days after birth has been newly proposed as the postnewborn period, which renews the divides of infant age (9). According to the new concept, the early life aged less than 1 year should be divided into the neonatal period ( $\leq 28$ days after birth), post-newborn period (from $>28$ days to $<100$ days), and modified infant period (from $\geq$ 100 days to 1 year). Meanwhile, the most important characteristics in the post-newborn period differing from the other two periods have been suggested: (1) different fatal diseases and mortality rate; (2) some diseases inherited from the newborn period requiring early and prompt treatment; (3) some peculiar diseases during this period requiring more attention; (4) either similar or different im- 
mune function; and (5) rapid growth and uneven development of organ systems. In the post-newborn period, infants should depend completely on breast milk except for some specific reasons. Evidence also supports the relationship between breastfeeding and health benefits in childhood and adults, including promoting long-term intestinal homeostasis (10), preventing gastrointestinal and respiratory tract infections $(11,12)$, decreasing risk of obesity and rheumatoid arthritis $(13,14)$, promoting receptive language intelligence and recognition development $(15,16)$, and regulating immune function (17). All these beneficial effects may be in virtue of some special matters in breast milk $(18,19)$. Establishment of the new concept may help to further reveal the nature of life, reduce infant mortality and improve the quality of life. It may also be useful to better understand the developmental origins of health and disease (8). Up until now, there has been no report referring to epidemiological data in the defined period.

\section{Objectives}

In the present study, mortality and etiology in a cohort of infants hospitalized over a ten-year period were surveyed and the differences were compared in the neonatal, post-newborn, and modified infant periods.

\section{Methods}

Public hospitals are divided into 3 grades: grade I, grade II, and grade III. A neonatal transfer collaboration network was initiated in 1999. In 2013, this network included 72 hospitals. Out of all of them, 12 hospitals belong to grade I, 30 to grade II, and 18 to grade III. The other 12 private hospitals which had a department of obstetrics and gynecology but did not have a department of pediatrics were excluded from the survey. All grade I hospitals were also excluded because they only provided basic medical care and all infants needing critical care had to be transferred to grade II and grade III hospitals.

Stratified randomized sampling was enforced in the selection of hospitals. One-third of grade II or grade III hospitals in each grade were included according to the stratified sampling method. A table of random numbers concealed in opaque envelopes was used to allocate and blindly randomize hospitals. After documenting the hospital's consent, 10 grade II hospitals and 6 grade III hospitals were randomly selected to join the survey. Two hospitals were excluded from the survey for the following causes: one could not offer the necessary 10-year data, while another ultimately decided to withdraw from the survey. Finally, 14 hospitals were included in the surveillance.
The life period of an infant was divided into 3 continuous periods: neonatal period ( 0 - 28 days), post-newborn period (from $>28$ days to $<100$ days) and modified infant period (from $\geq 100$ days to 1 year). The infants in the hospitals between January 1, 2004 and December 31, 2013 were included. Data of dead infants included birth weight (BW), gestational age (GA), gender, mode of delivery, mode of feeding, etiologies, and time of death were collected according to medical records.

The diagnoses of neonatal asphyxia, respiratory distress syndrome (RDS), pneumonia, encephalopathy of prematurity, retinopathy of prematurity, necrotizing enterocolitis, BPD and CHD were according to the manual of neonatal care (20). Sudden infant death syndrome (SIDS) was diagnosed according to the reported study (21). Preterm-associated disease (PAD) usually appeared as complications and sequelae of prematurity, which was used to assess the effects of prematurity for long-term prognosis (22). Here, it included four diseases: encephalopathy of prematurity, retinopathy of prematurity, necrotizing enterocolitis and BPD. Otherwise, the definition of breastfeeding means exclusively feeding with breast milk (no other food or drink) for the first six months after birth according to the World Health Organization (23).

\subsection{Statistical Analysis}

Categorical variables were compared using the $\chi 2$ test or the Fisher's test. Differences in the primary and other categorical outcomes were estimated together with 95\% confidence intervals. All analyses were carried out using computer software (SPSS 16.0 for Windows). A P value less than 0.05 was regarded as statistically significant.

\section{Results}

The survey was enforced in china between January 1,2004 and December 31, 2013. Overall, 155463 infants aged 0 - 1 year $(61729,21330$, and 72404 in the neonatal, postnewborn and modified infant period respectively) were enrolled in the survey. The total gender (female: male) ratio was 85504: 69959. The gender (female: male) ratio was 34568: 27161 in neonatal, 11945: 9385 in post-newborn, and 38991: 33413 in modified infant period respectively. The total infant mortality was 6.16\% (959/155463). Mortalities in the neonatal, post-newborn, and modified infant periods were 10.1\% (623/61729), 6.9\% (148/21330), and 2.6\% (188/72404) respectively, which showed a significant difference $(P=0.000)$. In post hoc analysis, significant differences were found in $2010(\mathrm{P}=0.012)$ and $2012(\mathrm{P}=0.001)$ between neonatal and post-newborn periods, and from 2004 to $2013(\mathrm{P} \leq 0.001)$ between post-newborn and modified infant periods except for $2012(\mathrm{P}=0.883)$. 
Among these dead infants, 28.4\% (272/959) were exclusively fed breast milk, 59.0\% (566/959) ate formula and $12.6 \%$ (118/959) had mixed feeding. The total prevalence of exclusive breastfeeding was 27.3\% (42401/155463), with $20.0 \%$ (12346/61729) in the neonatal period, $44.5 \%$ (9492/21330) in the post-newborn period and $28.4 \%$ (20563/72404) in the modified infant period, which also showed a significant difference $(P=0.000)$. The clinical characteristics of dead infants at birth included BW, GA, gender, mode of delivery, and mode of feeding which are shown in Table 1.

\begin{tabular}{|c|c|}
\hline & Dead Infants \\
\hline \multicolumn{2}{|l|}{ BW, g } \\
\hline$<2500$ & 311 \\
\hline$\geq 2500$ and $<4000$ & 617 \\
\hline$\geq 4000$ & 31 \\
\hline \multicolumn{2}{|l|}{ GA, weeks } \\
\hline$<37$ & 270 \\
\hline$\geq 37$ and $<42$ & 677 \\
\hline$\geq 42$ & 12 \\
\hline \multicolumn{2}{|l|}{ Gender } \\
\hline Female & 419 \\
\hline Male & 540 \\
\hline \multicolumn{2}{|l|}{ Delivery } \\
\hline Vaginal labor & 302 \\
\hline Caesarean & 657 \\
\hline \multicolumn{2}{|l|}{ Mode of feeding } \\
\hline Pure breast & 272 \\
\hline Formula & 566 \\
\hline Mixed & 121 \\
\hline
\end{tabular}

Figure 1 shows the changes in mortality during 2004 - 2013. The total infant mortality was decreased from $8.9 \%$ to $4.9 \%$. Mortality in the neonatal period and postnewborn period was decreased by $42.8 \%$ [14.0\% (42/2918) vs $8.0 \%$ (71/9385), $\mathrm{P}=0.001]$ and $50.0 \%$ [14.0\% (11/773) vs $7 \%$ (32/4448), $\mathrm{P}=0.048]$ respectively, whereas mortality in the modified infant period remained at a similar level of about 2.0\%. At the same time, yearly mortality showed a significant difference among the three periods ( $\mathrm{P} \leq 0.001)$.

Figure 2 shows the changing trends of cause-specific mortality in the neonatal period from 2004 to 2013. Overall, RDS, neonatal asphyxia and CHD were three main causes of death. The proportion of death from asphyxia showed a gradually decreasing trend from $35.7 \%$ to $28.2 \%$, but that from RDS indicated an inverse trend from $28.6 \%$ to $33.8 \%$.

Figure 3 shows the changing trends of cause-specific mortality in the post-newborn period from 2004 to 2013. The three main causes of death in this period were pneumonia, CHD and PAD. During the 10 years, mortality of pneumonia and CHD were kept at a nearly stable level, but mortality of PAD showed an obvious increased trend from 9.1\% to $15.5 \%$.

Figure 4 shows the changing trends of cause-specific mortality in the modified infant period from 2004 to 2013. In this period, the three main causes of death were pneumonia, CHD and accidents. Although pneumonia and CHD still remained the two most common causes of death, accidents turned out to be the third most important cause of death instead of PAD in the post-newborn period.

Some major causes of death appearing simultaneously in the neonatal, post-newborn, and modified infant period were compared and are shown in Table 2 . There was a significant difference in mortality of PAD (0.7\% vs $1.3 \%$ vs $0.2 \%$, $\mathrm{P}=0.000$ ), pneumonia ( $0.6 \%$ vs $2.0 \%$ vs $0.8 \%, \mathrm{P}=0.000$ ), CHD (1.0\% vs $1.6 \%$ vs $0.4 \%, \mathrm{P}=0.000)$, and SIDS ( $0.5 \%$ vs $0.7 \%$ vs $0.2 \%, \mathrm{P}=0.001$ ) among the three periods respectively. Longitudinally (from the neonatal period to the modified infant period), mortality of the four diseases was shown as an inverse "U" shape change, and the highest mortality appeared in the post-newborn period (Figure 5).

Effects of breastfeeding on the major causes of death appearing simultaneously in the neonatal, post-newborn, and modified infant period were compared and are shown in Table 3. Except for mortality of pneumonia (2.0 vs $2.2 \%$ vs $1.4 \%, P=0.177)$, there was a significant difference in mortality of PAD (2.4\% vs $1.2 \%$ vs $0.6 \%, \mathrm{P}=0.000)$, CHD (3.0\% vs $1.6 \%$ vs $0.7 \%, \mathrm{P}=0.000)$, and SIDS $(1.0 \%$ vs $0.9 \%$ vs $0.3 \%, \mathrm{P}=$ $0.000)$ among the three periods.

\section{Discussion}

To obtain epidemiological data of infant mortality and etiology, the present multicenter ten-year surveillance was conducted. The results showed that mortality in the postnewborn period was found to be significantly different from that in neonatal period and modified infant period from 2004 to 2013. Meanwhile, the three main causes of death were different among the three periods. Moreover, four major causes of death appearing simultaneously in the three periods also showed significant differences. The major diseases including PAD, pneumonia, SIDS and CHD which showed inverse "U" shape changes from the neonatal period to the modified infant period, and the highest mortality appeared in the post-newborn period. To our knowledge, this is the first study on epidemiological data supporting the new concept of the post-newborn period. 


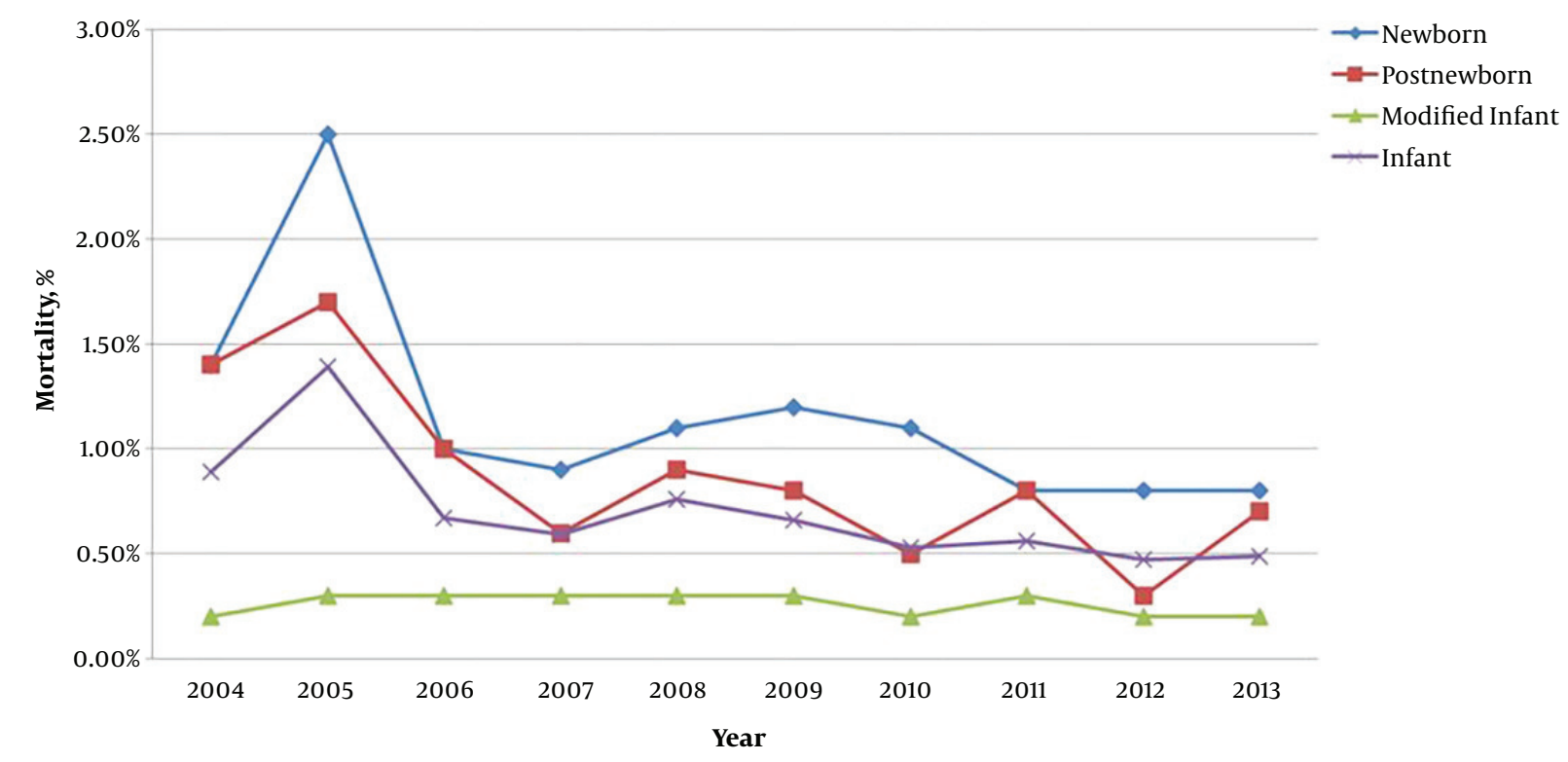

Figure 1. Trends in mortality in west China during 2004 - 2013 in the neonatal period ( $\leq 28$ days), post-newborn period ( $>28$ days to $<100$ days), modified infant period $(\geq$ 100 days to 1 year $)$ and infant period ( $0-1$ year $)$.

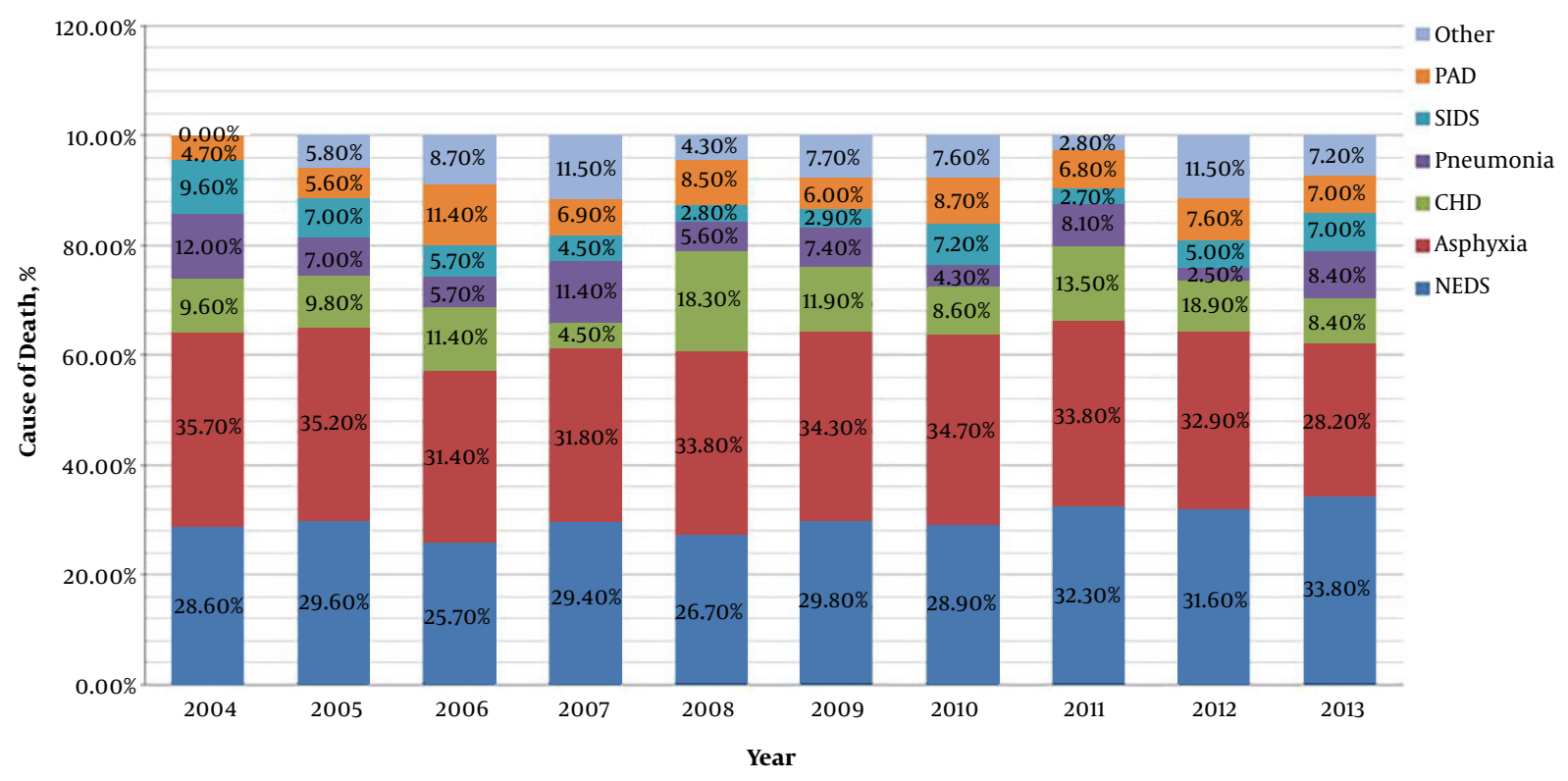

Figure 2. Trends in proportional contribution of the most common causes of death to the total numbers of death in neonatal period during 2004 - 2013. CHD: congenital heart disease. NRDS, neonatal respiratory distress syndrome; SIDS, sudden infant death syndrome; PAD, premature-associated disease including encephalopathy of prematurity, retinopathy of prematurity, necrotizing enterocolitis and bronchopulmonary dysplasia.

Infant mortality has gradually dropped down with an obvious imbalance in different countries and areas (2426). Neonatal mortality in the United States in 2006 has dropped by nearly half as compared with that in 1980 (from $8.48 \%$ to $4.45 \%$ ) (27), whereas it has decreased by $70 \%$ in China in 2008 as compared with that in 1990 (from $34.0 \%$ to $10.2 \%$ ) (28). A study referring to 11-year provincial-level time-series analyses in Mozambique showed that neonatal mortality in different provinces ranged from $13.6 \%$ to $4.2 \%$, and the differences might be most strongly associated with 


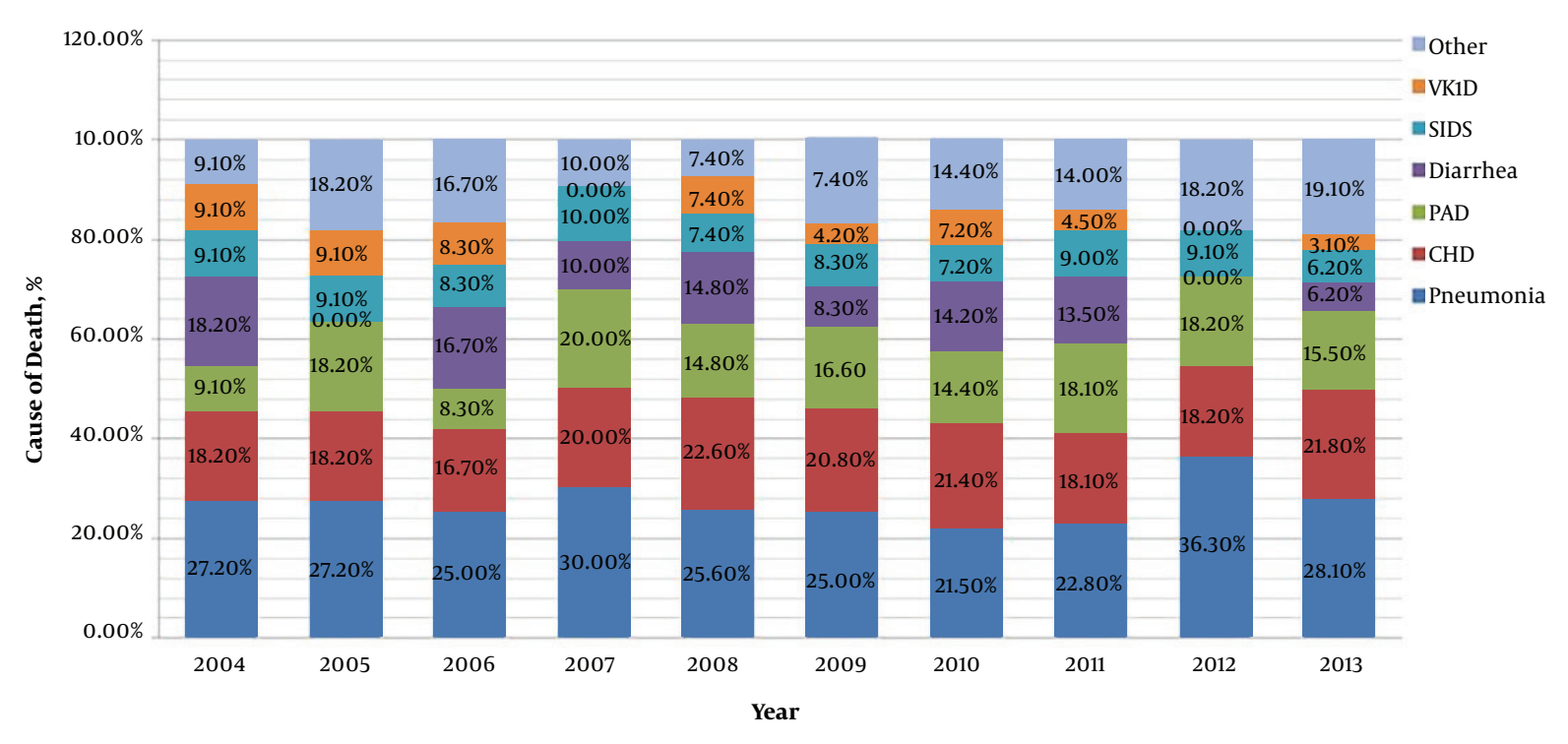

Figure 3. Trends in proportional contribution of the most common causes of death to the total numbers of death in post-newborn period during 2004 - 2013. VK1D, vitamin K1 deficiency; SIDS, sudden infant death syndrome; PAD, premature-associated disease including encephalopathy of prematurity, retinopathy of prematurity, necrotizing enterocolitis and bronchopulmonary dysplasia; CHD, congenital heart disease.

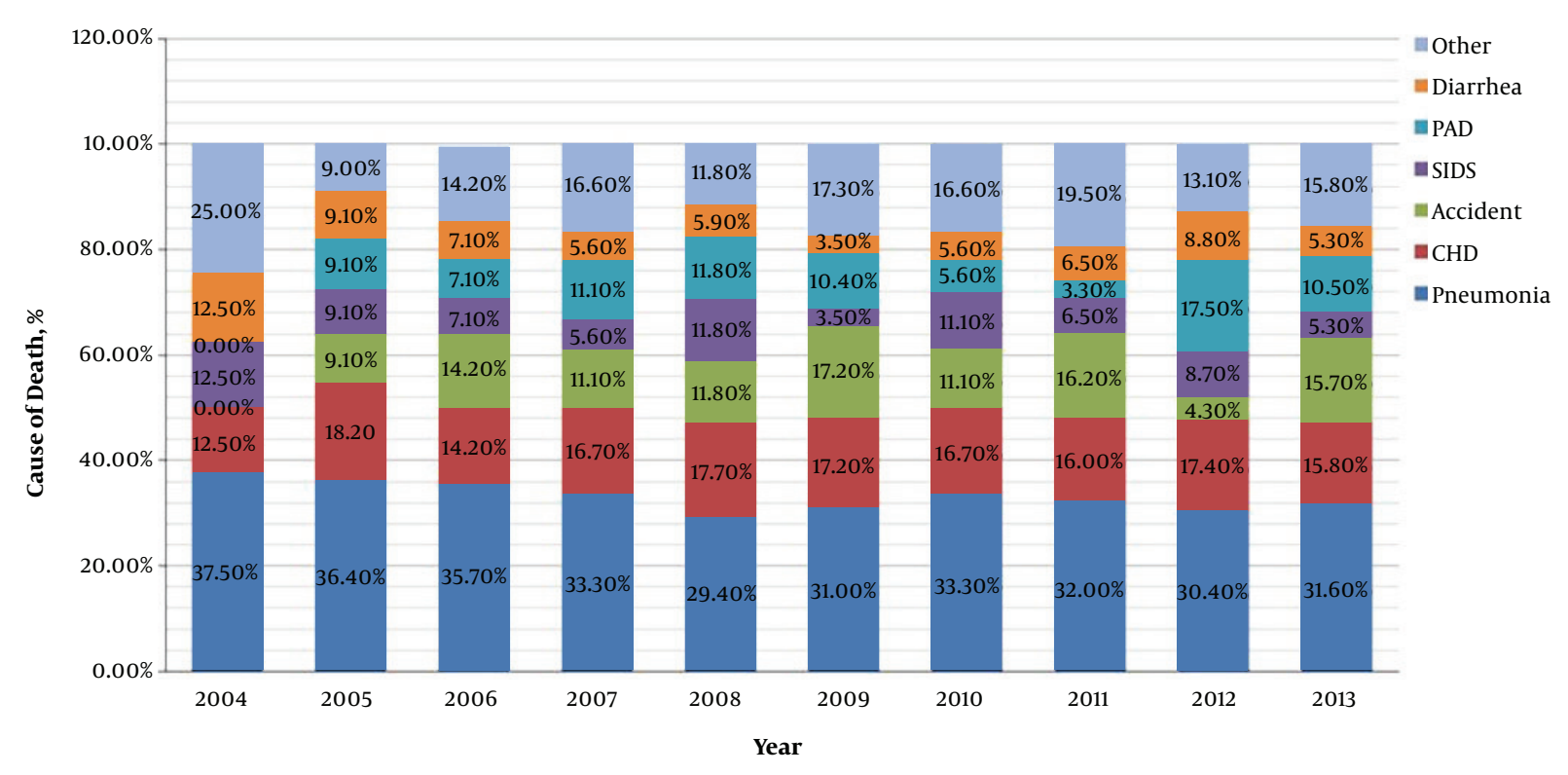

Figure 4. Trends in proportional contribution of the most common causes of death to the total numbers of death in modified infant period during 2004-2013. PAD, prematureassociated disease including encephalopathy of prematurity, retinopathy of prematurity, necrotizing enterocolitis and bronchopulmonary dysplasia; SIDS: sudden infant death syndrome; CHD, congenital heart disease.

institutional birth attendance, maternal and child nurse density and overall health workforce density (26). Infant mortality in developed areas including North America and Europe in 2002 dropped by half as compared with that in 1990 (from $14 \%$ to $7 \%$ ), whereas it only dropped from $75 \%$ to
$61 \%$ in developing areas. Meanwhile, the average mortality of the world was from $68 \%$ to $55 \%$ (24). In the United States, The infant mortality rate in 2013 was $5.96 \%$, which did not change significantly from the rate in 2012 (29). In China, infant mortality has also obviously decreased in the 


\begin{tabular}{|c|c|c|c|c|c|c|c|c|}
\hline \multirow{2}{*}{ Causes of Death } & \multicolumn{2}{|c|}{ Neonatal Period } & \multicolumn{2}{|c|}{ Post-Newborn Period } & \multicolumn{2}{|c|}{ Infant Period } & \multicolumn{2}{|c|}{ PValue } \\
\hline & Death $(N=623)$ & $\begin{array}{l}\text { Hospitalization } \\
(\mathrm{N}=61729)\end{array}$ & Death $(N=148)$ & $\begin{array}{l}\text { Hospitalization } \\
\quad(\mathbf{N}=\mathbf{2 1 3 3 0})\end{array}$ & Death $(\mathrm{N}=\mathbf{1 8 8})$ & $\begin{array}{l}\text { Hospitalization } \\
\quad(\mathrm{N}=\mathbf{7 2 4 0 4})\end{array}$ & & \\
\hline PAD, yes:No. (\%) & $45: 578(7.8)$ & $45: 61784(0.7)$ & 27:121(22.3) & $27: 21303(1.3)$ & 17:171(10.0) & $17: 72387(0.2)$ & 0.000 & 0.000 \\
\hline $\begin{array}{l}\text { Pneumonia, } \\
\text { yes:No. (\%) }\end{array}$ & $38: 585(6.5)$ & $38: 61691(0.6)$ & $43: 105(41.0)$ & $43: 21287(2.0)$ & $61: 127(48.0)$ & $61: 72343(0.8)$ & 0.000 & 0.000 \\
\hline CHD, yes:No. (\%) & $63: 560(11.3)$ & $63: 61666(1.0)$ & 33:115 (33.0) & $33: 21297(1.6)$ & 31:157 (19.7) & $31: 72373(0.4)$ & 0.000 & 0.000 \\
\hline SIDS, yes:No. (\%) & $33: 590(5.6)$ & $33: 61696(0.5)$ & $14: 134(10.4)$ & $14: 21316(0.7)$ & $14: 174(8.0)$ & $14: 72390(0.2)$ & 0.139 & 0.001 \\
\hline
\end{tabular}

Abbreviations: CHD, congenital heart disease; PAD, premature-associated disease including encephalopathy of prematurity, retinopathy of prematurity, necrotizing enterocolitis and bronchopulmonary dysplasia; SIDS, sudden infant death syndrome.

Table 3. Effects of Breastfeeding on the Major Causes of Death During the Neonatal, Post-Newborn, and Modified Infant Period ${ }^{\mathrm{a}}$

\begin{tabular}{|c|c|c|c|c|c|c|c|c|}
\hline & \multicolumn{2}{|c|}{ Neonatal Period } & \multicolumn{2}{|c|}{ Post-Newborn Period } & \multicolumn{2}{|c|}{ Infant Period } & \multicolumn{2}{|c|}{ PValue } \\
\hline & Death $(N=623)$ & $\begin{array}{l}\text { Breastfeeding } \\
\quad(\mathrm{N}=\mathbf{1 2 3 4 6})\end{array}$ & Death $(N=148)$ & $\begin{array}{l}\text { Breastfeeding } \\
\quad(\mathrm{N}=9492)\end{array}$ & Death $(N=188)$ & $\begin{array}{l}\text { Breastfeeding } \\
(\mathrm{N}=\mathbf{2 0 5 6 3})\end{array}$ & & \\
\hline PAD & $30(4.8)$ & $30(2.4)$ & $11(7.4)$ & $11(1.2)$ & $12(6.4)$ & $12(0.6)$ & 0.387 & 0.000 \\
\hline Pneumonia & $25(4.0)$ & $25(2.0)$ & $21(14.2)$ & $21(2.2)$ & $28(17.5)$ & $28(1.4)$ & 0.000 & 0.177 \\
\hline CHD & $37(5.9)$ & $37(3.0)$ & $15(10.1)$ & $15(1.6)$ & $15(8.0)$ & $15(0.7)$ & 0.166 & 0.000 \\
\hline SIDS & $12(1.9)$ & $12(1.0)$ & $9(6.1)$ & $9(0.9)$ & $6(3.2)$ & $6(0.3)$ & 0.022 & 0.000 \\
\hline
\end{tabular}

Abbreviations: CHD, congenital heart disease; PAD, premature-associated disease including encephalopathy of prematurity, retinopathy of prematurity, necrotizing enterocolitis and bronchopulmonary dysplasia; SIDS, sudden infant death syndrome.

${ }^{\mathrm{a}}$ Values are expressed as No. (\%)

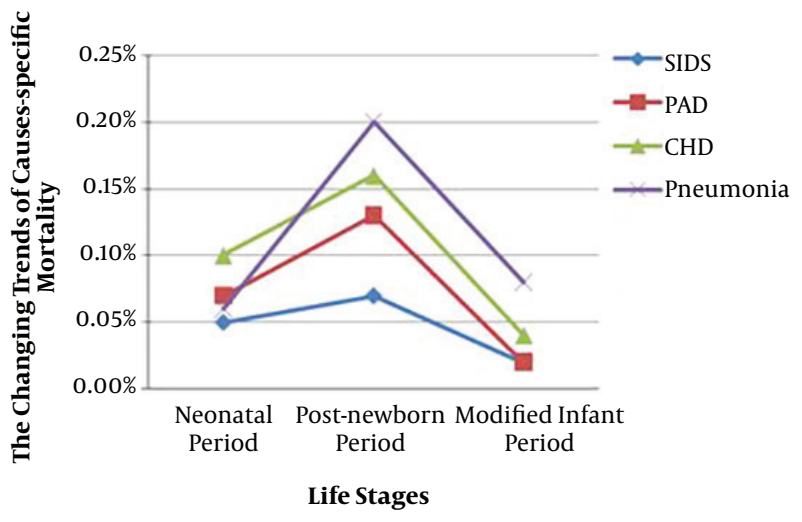

Figure 5. Inverse "U" shape changes of the mortality of PAD, pneumonia, CHD, and SIDS. PAD, premature-associated disease including encephalopathy of prematurity, retinopathy of prematurity, necrotizing enterocolitis and bronchopulmonary dysplasia; SIDS, sudden infant death syndrome; CHD, congenital heart disease.

past ten years. Compared with $24.1 \%$ in 2002 , it accounted for $12.1 \%$ in 2012 , and in 2013 , it was down to $9.5 \%$. In our cohort of 155463 infants, the neonatal and infant mortality decreased from $14 \%$ and $8.9 \%$ in 2004 to $8 \%$ and $4.9 \%$ in 2013, respectively. A survey enforced in 188 countries referring to 6.3 million children under 5 who died from 1970 to 2013 showed that compared with $33.4 \%$ in 1970 and $37.4 \%$ in 1990, neonatal deaths accounted for $41.6 \%$ of under- 5 deaths, and would account for $44.9 \%$ in 2030 (30), and the trend indicated that neonatal deaths would play more and more important role during childhood.

The most interesting finding in the present study was that there was a significant different mortality rate among neonatal, post-newborn, and modified infant periods, and these differences mainly appeared between post-newborn and modified infant periods. In other words, there was more intimate association of causes of death between neonatal and post-newborn periods. Actually, the etiology of infant deaths varied from different countries to areas (31). In the worldwide, three main causes of 2.9 million annual neonatal deaths were attributed to preterm birth complications (34.5\%), intrapartum conditions (24.1\%) and infections (20.7\%) (22). In developed countries, the three main causes of death in infants were congenital abnormalities, perinatal disease and SIDS (32-34), whereas in developing countries, they were neonatal disease, infection and congenital abnormalities $(31,35)$. In the United States, the most leading causes of infant deaths in 2013 were congenital abnormalities, low birth weight, maternal complications, and SIDS (29), while in China, they were birth asphyxia, preterm birth complications, congenital abnormalities and pneumonia (36). Data from 2007 - 2008 in Mozambique showed that $35 \%$ of deaths were attributable 
to bacterial sepsis, and 10\% to complications of pregnancy, labor, and delivery during the neonatal period. Other major causes of death in neonates were fetal development disorders (6\%), malaria (6\%), hypoxia and asphyxia (6\%), and pneumonia (4\%) (37). The present survey showed that the three main causes of death in neonatal infants were RDS, neonatal asphyxia and CHD. The leading causes of death in the post-newborn period were different but had an intimate association with those in the neonatal period. During the 10-year study period, the mortality of neonatal asphyxia gradually decreased, which on one hand induced a higher survival rate in neonates, but on the other hand, might lead to more infants dying from PAD in the postnewborn period.

CHD was another important cause of death during the infant period, which accounted for nearly $28 \%$ of all major congenital anomalies (38). A meta-analysis in 2011 reported total CHD birth prevalence increased with significant geographical differences from 0.6 per 1,000 live births in 1930 to 9.1 per 1,000 live births after 1995. Among these infants with CHD, about $1 \%$ to $2 \%$ babies needed early treatment as soon as possible (39). In the present study, CHD-induced infant mortality was $0.8 \%$, which was obviously higher than $0.12 \%$ in 2013 in the United States (29), and high death proportion of CHD in both neonatal (11.3\%) and post-newborn (33.0\%) periods indicated that these infants might not accept early detection and effective intervention (40). In this sense, pulse oximetry plus clinical assessment for detection of major CHD, especially critical CHD, might be feasible and reliable all over the world (41).

SIDS is defined as the sudden unexplained death of an infant younger than one year of age. SIDS usually occurs in a previously healthy infant with a thorough post mortem examination failing to demonstrate adequate causes of death (42). Overall, the rate of SIDS has decreased from 1.2 deaths per 1,000 live births in 1994 to 0.57 deaths per 1,000 live births in 2002 (43). In the United States, SIDS was the fourth leading cause of death in infancy, and it was about 0.43 per 1,000 infants in 2012, which showed a decrease with 0.40 per 1,000 infants in 2013 (29). Moreover, SIDS has been indicated to have a peak incidence at 2 to 4 months of age (44) In our survey, SIDS also showed inverse "U" shape changes in infancy, and the highest mortality appeared in the post-newborn period. Additionally, there were similar trends in PAD, pneumonia and CHD. The results strongly suggested that much attention should be paid to the newly proposed concept of post-newborn period in early life.

As is known, growth and development are the most important characteristics of infants and sensitive markers of their health, disease status and adequate nutrition (45), and breastfeeding is the most important nutritional factor in early life. Hence, to further verify the effects of a new concept on the mortality of the three periods, we also assessed the relations between the four diseases and breastfeeding. Our study demonstrated that, except for pneumonia, there were obvious associations between mortality of PAD, CHD and SIDS and breastfeeding among the three periods. We concluded that lower rate of breastfeeding might induce these differences. In 2013, an investigation referring to 90 Chinese cities showed that the prevalence of exclusive breastfeeding was $15.66 \%$. Another report from the World Bank in 2008 indicated that the prevalence of exclusive breastfeeding was $67 \%$ in 1998 , but decreased rapidly to $27.6 \%$ in 2008 , with only $16 \%$ in big cities (46). These studies suggested a low rate and reduced trend of breastfeeding in China. Chung et al. reviewed the global breastfeeding rate as follows (47): In the USA, breastfeeding rate showed an increased trend from 2003 to 2009, and they were $36.0 \%$ and $16.3 \%$ at the ages of 3 and 6 months, respectively in 2009. In the same year in Korea, they were $50.0 \%$ and $11.4 \%$ at the two time points, respectively. In England, they were $17 \%$ and $12 \%$ in 2010 . The highest rate appeared in Hungary with 95\%. On average, almost 50\% infants less than 3 months are breastfed. But, by 6 months, less than $25 \%$ are breastfed. In the present study, the prevalence of breastfeeding was $27.3 \%$, with $20.0 \%$ in the neonatal period, $44.5 \%$ in the post-newborn period and $28.4 \%$ in the modified infant period. Our report of breastfeeding rate ranked in the middle and demonstrated an obvious reduction of breastfeeding rate in the modified infant period, which indicated the duration of breastfeeding was less than six months as recommended by the World Health Organization.

There is a total trend that more and more preterm newborns survive, and the gestational age of the survivors is also becoming smaller and smaller. Hence, neonatal asphyxia might lose the importance as the first cause of death. In addition to CHD or other congenital diseases, PAD would become the most common cause of death in the newborn and post-newborn periods in developing countries. A few survived infants suffered neurologic impairment and metabolic diseases in childhood and/or adulthood (48-50). These complications and sequelae would induce increased medical and social burdens and constitute a challenge for both public health organizations and healthcare providers. This survey might provide a new important insight into understanding the importance of early life in health and disease.

There are some limitations in the present study. Firstly, the selection of hospitals did not consider the difference of economy in different areas. Secondly, limited number of involved hospitals might mean some potential bias. These problems can be overcome by a national survey in the future. Given the potential limitations, future trials are 
needed.

In summary, the difference in mortality and etiology of the neonatal, post-newborn, and modified infant periods supports the concept of the post-newborn period. Further research is needed to better understand its clinical significance.

\section{Acknowledgments}

We thank Dr. Yijun Liu and Karen M. von Deneen from University of Florida for their valuable comments and suggestions that greatly improved the presentation of this article.

\section{Footnotes}

Authors' Contribution: Long Chen conceptualized and designed the study, reviewed the documents of patients, drafted and revised the initial manuscript, and approved the final manuscript as submitted. Xingwang Zhu reviewed the documents of patients, drafted and revised the initial manuscript and approved the final manuscript as submitted. Yuan Shi conceptualized and designed the study, revised the initial manuscript and approved the final manuscript as submitted.

Conflict of Interests: The authors declare no conflicts of interest.

\section{Funding/Support: There is no support.}

Informed Consent: The informed consent obtained from the parents.

\section{References}

1. Blencowe H, Cousens S, Oestergaard MZ, Chou D, Moller AB, Narwal R, et al. National, regional, and worldwide estimates of preterm birth rates in the year 2010 with time trends since 1990 for selected countries: A systematic analysis and implications. Lancet. 2012;379(9832):2162-72. doi: 10.1016/S0140-6736(12)60820-4. [PubMed: 22682464].

2. St Clair C, Norwitz ER, Woensdregt K, Cackovic M, Shaw JA, Malkus H, et al. The probability of neonatal respiratory distress syndrome as a function of gestational age and lecithin/sphingomyelin ratio. Am J Perinatol. 2008;25(8):473-80. doi: 10.1055/s-0028-1085066. [PubMed: 18773379]. [PubMed Central: PMC3095020].

3. Liu L, Johnson HL, Cousens S, Perin J, Scott S, Lawn JE, et al. Global, regional, and national causes of child mortality: An updated systematic analysis for 2010 with time trends since 2000. Lancet. 2012;379(9832):2151-61. doi: 10.1016/S0140-6736(12)60560-1. [PubMed: 22579125].

4. Owen LS, Cheong JLY, Davis PG. Bronchopulmonary dysplasia as a trial endpoint: Time for re-evaluation? Lancet Child Adolesc Health. 2019;3(12):842-4. doi: 10.1016/S2352-4642(19)30321-9. [PubMed: 31585808].

5. Blackmon LR, Fanaroff AA, Raju TN; National Institute of Child Health; Human Development. Research on prevention of bilirubin-induced brain injury and kernicterus: National Institute of Child Health and Human Development conference executive summary. 2003.
Pediatrics. 2004;114(1):229-33. doi: 10.1542/peds.114.1.229. [PubMed: 15231933].

6. Davidson S, Quinn GE. The impact of pediatric vision disorders in adulthood. Pediatrics. 2011;127(2):334-9. doi: 10.1542/peds.2010-1911. [PubMed: 21199855].

7. Wacker-Gussmann A, Ehringer-Schetitska D, Herceg-Cavrak V, Hidvegi E, Jakab AE, Petropoulos A, et al. Prevention of delayed diagnosis in congenital heart disease. Cardiol Young. 2019;29(5):730-1. doi: 10.1017/S1047951119000064. [PubMed: 31145053].

8. Barker DJ. The origins of the developmental origins theory. J Intern Med. 2007;261(5):412-7. doi: 10.1111/j.1365-2796.2007.01809.x. [PubMed: 17444880].

9. Chen L, Li J, Wang N, Shi Y. Post-newborn: A new concept of period in early life. Lecture notes in electrical engineering. 269. New York City: Springer; 2014. p. 1343-50. doi:10.1007/978-94-007-7618-0_143.

10. Rogier EW, Frantz AL, Bruno ME, Wedlund L, Cohen DA, Stromberg AJ, et al. Secretory antibodies in breast milk promote long-term intestinal homeostasis by regulating the gut microbiota and host gene expression. Proc Natl Acad Sci U S A. 2014;111(8):3074-9. doi 10.1073/pnas.1315792111. [PubMed: 24569806]. [PubMed Central: PMC3939878].

11. Gardner H, Green K, Gardner A, Geddes D. Maternal and Infant Health in Abu Dhabi: Insights from key informant interviews. Int J Environ Res Public Health. 2019;16(17). doi: 10.3390/ijerph16173053. [PubMed: 31443539]. [PubMed Central: PMC6747237].

12. Li R, Dee D, Li CM, Hoffman HJ, Grummer-Strawn LM. Breastfeeding and risk of infections at 6 years. Pediatrics. 2014;134 Suppl 1:S13-20. doi: 10.1542/peds.2014-0646D. [PubMed: 25183750]. [PubMed Central: PMC4258846].

13. Yamakawa M, Yorifuji T, Inoue S, Kato T, Doi H. Breastfeeding and obesity among schoolchildren: A nationwide longitudinal survey in Japan. JAMA Pediatr. 2013;167(10):919-25. doi: 10.1001/jamapediatrics.2013.2230. [PubMed: 23939787].

14. Adab P, Jiang CQ, Rankin E, Tsang YW, Lam TH, Barlow J, et al. Breastfeeding practice, oral contraceptive use and risk of rheumatoid arthritis among Chinese women: The Guangzhou biobank cohort study. Rheumatology (Oxford). 2014;53(5):860-6. doi: 10.1093/rheumatology/ket456. [PubMed: 24395920].

15. Belfort MB, Rifas-Shiman SL, Kleinman KP, Guthrie LB, Bellinger DC, Taveras EM, et al. Infant feeding and childhood cognition at ages 3 and 7 years: Effects of breastfeeding duration and exclusivity.JAMA Pediatr. 2013;167(9):836-44. doi: 10.1001/jamapediatrics.2013.455. [PubMed: 23896931]. [PubMed Central: PMC3998659].

16. Liu B, Zupan B, Laird E, Klein S, Gleason G, Bozinoski M, et al Maternal hematopoietic TNF, via milk chemokines, programs hippocampal development and memory. Nat Neurosci. 2014;17(1):97105. doi: 10.1038/nn.3596. [PubMed: 24292233]. [PubMed Central: PMC6169993].

17. Ardeshir A, Narayan NR, Mendez-Lagares G, Lu D, Rauch M, Huang Y, et al. Breast-fed and bottle-fed infant rhesus macaques develop distinct gut microbiotas and immune systems. Sci Transl Med. 2014;6(252):252ra120. doi: 10.1126/scitranslmed.3008791. [PubMed: 25186175]. [PubMed Central: PMC4362692].

18. Fouda GG, Jaeger FH, Amos JD, Ho C, Kunz EL, Anasti K, et al Tenascin-C is an innate broad-spectrum, HIV-1-neutralizing protein in breast milk. Proc Natl Acad Sci U S A. 2013;110(45):18220-5. doi: 10.1073/pnas.1307336110. [PubMed: 24145401]. [PubMed Central: PMC3831436].

19. McElroy SJ, Castle SL, Bernard JK, Almohazey D, Hunter CJ, Bell BA, et al. The ErbB4 ligand neuregulin-4 protects against experimental necrotizing enterocolitis. Am J Pathol. 2014;184(10):2768-78. doi: 10.1016/j.ajpath.2014.06.015. [PubMed: 25216938]. [PubMed Central: PMC4715213] 
20. Cloherty JP, Eichenwald EC, Stark AR. Manual of neonatal care. 6th ed. Philadelphia , Pennsylvania , USA: Lippincott Williams \& Wilkins; 2008.

21. Pretorius KA, Mackert M, Wilcox GB. Sudden infant death syndrome and safe sleep on twitter: Analysis of influences and themes to guide health promotion efforts. JMIR Pediatr Parent. 2018;1(2). e10435. doi: 10.2196/10435. [PubMed: 31518314]. [PubMed Central: PMC6715061].

22. Lawn JE, Blencowe H, Oza S, You D, Lee AC, Waiswa P, et al. Every Newborn: Progress, priorities, and potential beyond survival. Lancet. 2014;384(9938):189-205. doi: 10.1016/S0140-6736(14)60496-7. [PubMed: 24853593].

23. World Health Organization. Programs and projects, nutrition topics, exclusive breastfeeding. 2018, [cited 2013 June 15]. Available from: http: //www.who.int/nutrition/topics/exclusive_breastfeeding/en.

24. America Population Reference Bureau. The world population data sheet. 2018

25. Stoll BJ, Hansen NI, Bell EF, Shankaran S, Laptook AR, Walsh MC et al. Neonatal outcomes of extremely preterm infants from the NICHD Neonatal Research Network. Pediatrics. 2010;126(3):443-56 doi: 10.1542/peds.2009-2959. [PubMed: 20732945]. [PubMed Central PMC2982806].

26. Fernandes QF, Wagenaar BH, Anselmi L, Pfeiffer J, Gloyd S, Sherr $\mathrm{K}$. Effects of health-system strengthening on under-5, infant, and neonatal mortality: 11-year provincial-level time-series analyses in Mozambique. Lancet Glob Health. 2014;2(8):e468-77. doi 10.1016/S2214-109X(14)70276-1. [PubMed: 25103520]. [PubMed Central: PMC 4158849].

27. Heron M, Hoyert DL, Murphy SL, Xu J, Kochanek KD, Tejada-Vera B. Deaths: Final data for 2006. Natl Vital Stat Rep. 2009;57(14):1-134 [PubMed: 19788058].

28. Rudan I, Chan KY, Zhang JS, Theodoratou E, Feng XL, Salomon JA, et al. Causes of deaths in children younger than 5 years in China in 2008 Lancet. 2010;375(9720):1083-9. doi: 10.1016/S0140-6736(10)60060-8. [PubMed: 20346815].

29. Kochanek KD, Murphy SL, Xu J, Arias E. Mortality in the United States, 2013. NCHS Data Brief. 2014;(178):1-8. [PubMed: 25549183]

30. Wang H, Liddell CA, Coates MM, Mooney MD, Levitz CE, Schumacher $\mathrm{AE}$, et al. Global, regional, and national levels of neonatal, infant, and under-5 mortality during 1990-2013: A systematic analysis for the global burden of disease study 2013. Lancet. 2014;384(9947):95779. doi:10.1016/S0140-6736(14)60497-9. [PubMed: 24797572]. [PubMed Central: PMC4165626].

31. Jiang Z, Guo SF, Scherpbier RW, Wen CM, Xu XC, Guo Y. Determining optimal strategies to reduce maternal and child mortality in rural areas in Western China: An assessment using the lives saved tool. Biomed Environ Sci. 2015;28(8):606-10. doi: 10.3967/bes2015.084 [PubMed: 26383598].

32. Ogasawara K, Matsushita Y. Public health and multiple-phase mortality decline: Evidence from industrializing Japan. Econ Hum Biol. 2018;29:198-210. doi:10.1016/j.ehb.2018.04.001. [PubMed: 29684671].

33. Arntzen A, Samuelsen SO, Daltveit AK, Stoltenberg C. Post-neonatal mortality in Norway 1969-95: A cause-specific analysis. Int J Epidemiol. 2006;35(4):1083-9. doi:10.1093/ije/dyl047. [PubMed: 16556644].

34. Nordstrom ML, Cnattingius S, Haglund B. Social differences in Swedish infant mortality by cause of death, 1983 to 1986. Am J Public Health. 1993;83(1):26-30. doi: 10.2105/ajph.83.1.26. [PubMed: 8417602] [PubMed Central: PMC1694527].

35. Chen XY, Wang TY, Zheng QS. A retrospective study on the propor- tional mortality of hospitalized newborns and infants during 19862000. Chinese Med Record. 2007;8(7):39-40.

36. Yrjana JMS, Koski T, Torola H, Valkama M, Kulmala P. Very early introduction of semisolid foods in preterm infants does not increase food allergies or atopic dermatitis. Ann Allergy Asthma Immunol. 2018;121(3):353-9. doi:10.1016/j.anai.2018.06.029. [PubMed: 29981439].

37. Mozambique National Institute of Statistics USCB; US Centers for Disease Control Prevention. Mortality in Mozambique: Results from a 20072008 post-census mortality survey. Mozambique Chapel Hill, USA: National Institute of Statistics, Measure Evaluation; 2012.

38. Dolk H, Loane M, Garne E; European Surveillance of Congenital Anomalies Working Group. Congenital heart defects in Europe: Prevalence and perinatal mortality, 2000 to 2005. Circulation. 2011;123(8):841-9. doi: 10.1161/CIRCULATIONAHA.110.958405. [PubMed: 21321151].

39. van der Linde D, Konings EE, Slager MA, Witsenburg M, Helbing WA, Takkenberg JJ, et al. Birth prevalence of congenital heart disease worldwide: A systematic review and meta-analysis. J Am Coll Cardiol. 2011;58(21):2241-7. doi: 10.1016/j.jacc.2011.08.025. [PubMed: 22078432].

40. Chang RK, Gurvitz M, Rodriguez S. Missed diagnosis of critical congenital heart disease. Arch Pediatr Adolesc Med. 2008;162(10):969-74. doi: 10.1001/archpedi.162.10.969. [PubMed: 18838650].

41. Zhao QM, Ma XJ, Ge XL, Liu F, Yan WL, Wu L, et al. Pulse oximetry with clinical assessment to screen for congenital heart disease in neonates in China: A prospective study. Lancet. 2014;384(9945):74754. doi: 10.1016/S0140-6736(14)60198-7. [PubMed: 24768155].

42. Shipstone RA, Young J, Thompson JMD, Byard RW. An evaluation of pathologists' application of the diagnostic criteria from the San Diego definition of SIDS and unclassified sudden infant death. Int J Legal Med. 2019. doi: 10.1007/s00414-019-02126-w. [PubMed: 31317315].

43. Moon RY, Fu LY. Sudden infant death syndrome. Pediatr Rev. 2007;28(6):209-14. doi:10.1542/pir.28-6-209. [PubMed: 17545332].

44. Kinney HC, Thach BT. The sudden infant death syndrome. $N$ Engl J Med. 2009;361(8):795-805. doi: 10.1056/NEJMra0803836. [PubMed: 19692691]. [PubMed Central: PMC3268262].

45. Koletzko B, Beyer J, Brands B, Demmelmair H, Grote V, Haile G, et al. Early influences of nutrition on postnatal growth. Nestle Nutr Inst Workshop Ser. 2013;71:11-27. doi: 10.1159/000342533. [PubMed: 23502135].

46. Lei Y. Less than $16 \%$ prevalence of breastfeeding in Chinese cities in 2013. 2014. Available from: http://www.chinanews.com/gn/20130802/5118292.shtml.

47. Chung SH, Kim HR, Choi YS, Bae CW. Trends of breastfeeding rate in Korea (1994-2012): Comparison with OECD and other countries. J Korean Med Sci. 2013;28(11):1573-80. doi: 10.3346/jkms.2013.28.11.1573. [PubMed: 24265518]. [PubMed Central: PMC3835497].

48. Lega IC, Pole JD, Austin PC, Lau C, Nathan PC, Baxter NN. Diabetes risk in childhood cancer survivors: A population-based study. Can J Diabetes. 2018;42(5):533-9. doi: 10.1016/j.jcjd.2018.01.004. [PubMed: 29937232].

49. Barker DJ, Forsen T, Eriksson JG, Osmond C. Growth and living conditions in childhood and hypertension in adult life: A longitudinal study. J Hypertens. 2002;20(10):1951-6. doi: 10.1097/00004872200210000-00013. [PubMed: 12359972].

50. Isaacs EB, Morley R, Lucas A. Early diet and general cognitive outcome at adolescence in children born at or below 30 weeks gestation. $J$ Pediatr. 2009;155(2):229-34. doi: 10.1016/j.jpeds.2009.02.030. [PubMed: 19446846]. 